\title{
Human epididymis protein 4 promotes P-glycoprotein-mediated chemoresistance in ovarian cancer cells through interactions with Annexin II
}

\author{
QING LIU ${ }^{1}$, DA-WO LIU ${ }^{1}$, MING-JUN ZHENG ${ }^{2}$, LU DENG $^{3}$, HUI-MIN WANG ${ }^{4}$, SHAN JIN ${ }^{4}$, \\ JUAN-JUAN LIU ${ }^{1}$, YING-YING HAO ${ }^{1}$, LIAN-CHENG ZHU ${ }^{1}$ and BEI LIN ${ }^{1}$
}

\begin{abstract}
${ }^{1}$ Department of Obstetrics and Gynecology, Shengjing Hospital Affiliated to China Medical University, Shenyang,
Liaoning 110000, P.R. China; ${ }^{2}$ Department of Obstetrics and Gynecology, University Hospital, LMU Munich, D-80337 Munich, Germany; ${ }^{3}$ Department of Obstetrics and Gynecology, Hospital of Fudan University, Shanghai 200000; ${ }^{4}$ Department of Obstetrics and Gynecology, Liaoning Cancer Hospital and Institute, Shenyang, Liaoning 110000, P.R. China
\end{abstract}

Received August 17, 2020; Accepted March 16, 2021

DOI: $10.3892 / \mathrm{mmr} .2021 .12135$

\begin{abstract}
The aim of the present study was to investigate the effects of human epididymis protein 4 (HE4) on drug resistance and its underlying mechanisms. The associations among proteins were detected by immunoprecipitation and immunofluorescence assays. Then, stably transfected cell lines CAOV3-HE4-L and CAOV3-A2-L expressing HE4 short hairpin (sh)RNAs and ANXA2 shRNAs, respectively, were constructed. MTT assay, immunocytochemistry, western blotting, reverse transcription-quantitative polymerase chain reaction (RT-qPCR) and flow cytometry were employed to examine drug sensitivity, as well as the expression and activity of P-glycoprotein (P-gp). HE4 and P-gp in epithelial ovarian cancer tissues were assessed via immunohistochemistry. MicroRNAs that targeted the P-gp gene, ABCB1, were predicted using bioinformatics methods, and their expression was evaluated by RT-qPCR. The common signaling pathways shared by HE4, ANXA2 and P-gp were selected by Gene Set Enrichment Analysis (GSEA). The interaction of HE4, ANXA2 and P-gp were confirmed. P-gp expression was positively associated with HE4 and ANXA2 expression, respectively. Moreover, it was observed that there was no significant rescue of P-gp expression in CAOV3-A2-L cells following the administration of active $\mathrm{HE} 4$ protein. In addition, the expression of HE4 and P-gp in ovarian cancer tissues of drug-resistant patients were higher compared with that of the drug-sensitive group $(\mathrm{P}<0.05)$. Furthermore, the results revealed that hsa-miR-129-5p was significantly increased accompanied by decreased HE4 or ANXA2 expression and
\end{abstract}

Correspondence to: Dr Bei Lin, Department of Obstetrics and Gynecology, Shengjing Hospital Affiliated to China Medical University, 2 Sanhao Street, Shenyang, Liaoning 110000, P.R. China E-mail: prof_linbei@126.com

Key words: ovarian cancer, HE4, ANXA2, P-gp, drug resistance
P-gp expression in CAOV3-HE4-L and CAOV3-A2-L cells. GSEA analyses disclosed that HE4, ANXA2 and P-gp genes were commonly enriched in the signaling pathway involved in regulating the actin cytoskeleton. These results indicated that HE4 promotes P-gp-mediated drug resistance in ovarian cancer cells through the interactions with ANXA2, and the underlying mechanism may be associated with decreased expression of hsa-miR-129-5p and dysregulation of the actin cytoskeleton signaling pathway.

\section{Introduction}

Epithelial ovarian cancer (EOC) is the most lethal gynecological malignancy for which chemotherapy is an indispensable treatment option in patients of advanced cases. Despite significant progress in treatment, $\sim 70 \%$ of patients with ovarian cancer (OC) relapse within 2 years after surgery (1). The main reason for the high mortality rate of OC is drug resistance. Therefore, elucidation of the underlying molecular mechanisms is critical for improving therapeutic effects and prognosis.

Multiple drug resistance (multidrug resistance; MDR), a phenomenon whereby human tumors that acquire resistance to one type of therapy are found to be resistant to several other drugs that are often quite different in both structure and mode of action, has been recognized clinically for several decades (2). One of the classical mechanisms of MDR is increased expression of P-glycoprotein (P-gp), a drug efflux pump on the cell membrane. It has been well established that P-gp actively effluxes cytotoxic substrates such as paclitaxel and adriamycin, the first-line OC chemotherapy drugs $(3,4)$. Moreover, P-gp may have side effects that are independent of its drug efflux activity. Several authors have described the influences of P-gp on the function of proteins involved in regulatory pathways, including apoptotic progression (such as p53, caspase-3 and Pokemon) (5). Gibalová et al (6) demonstrated that even though platinum drugs are not substrates of P-gp, increased P-gp levels can induce platinum resistance in tumor cells. 
Human epididymis protein 4 (HE4), a secreted glycoprotein, has been recently characterized as a more sensitive OC biomarker than carbohydrate antigen 125 (CA125). The protein is overexpressed in patients with $\mathrm{OC}$ and is positively correlated with malignancy (7). Several recent clinical studies have demonstrated that HE4 is closely associated with prognosis and is effective in predicting recurrence and chemotherapeutic resistance $(8,9)$. A recent study by Ribeiro et al $(10)$ also reported that increased HE4 expression simultaneously induces resistance to paclitaxel and carboplatin in OC cells in vitro.

ANXA2, a calcium-dependent phospholipid-binding protein, acts as a fibrinolytic receptor to promote matrix remodeling, protein hydrolysis, neovascularization, and invasion and metastasis of malignant tumors (11-13). Previously, it was demonstrated that HE4 and ANXA2 are interacting proteins and HE4 requires ANXA2 to promote cancer cell invasion and metastasis. Invasion/metastasis and drug resistance are important biological characteristics of malignant tumors (14). Metastatic tumors are more resistant to chemotherapeutic drugs, suggesting an association between drug resistance and cancer invasion/metastasis. In breast cancer, ANXA2 interacts with P-gp and promotes the migration and invasion of drug-resistant tumor cells (15). Multiple studies have provided evidence of a significant association of ANXA2 with drug resistance in diverse malignant tumors (16-18). ANXA2 increases P-gp expression in gastric cancer cells by activating the MAPK signaling pathway, resulting in MDR of cancer cells (19).

Thus, HE4 could promote the malignant biological behavior of OC cells through interactions with ANXA2, and ANXA2 is closely associated with P-gp-mediated drug resistance. However, the mechanisms underlying the potential involvement of HE4 in the development of drug resistance in OC remain to be elucidated. In the present study, in order to analyze the role of HE4, ANXA2 and P-gp in drug resistance of OC, the expression of HE4, ANXA2 and P-gp were firstly detected in three OC cell lines. Then, the associations among HE4, ANXA2 and P-gp in ovarian cancer cells were investigated via immunoprecipitation (IP) and immunofluorescence (IF). To further explore whether HE4 affects P-gp-mediated drug resistance in $\mathrm{OC}$ and whether the effects require the involvement of ANXA2, stably transfected cell lines with low expression of HE4 and ANXA2 were constructed, respectively. A variety of techniques, including thiazolyl blue tetrazolium bromide (MTT) assay, immunocytochemistry, western blotting (WB), reverse transcription-quantitative polymerase chain reaction (RT-qPCR) and flow cytometry were employed to assess drug sensitivity, expression and activity of P-gp before and after the transfection. The expression of P-gp was additionally determined before and after the addition of active HE4 or ANXA2 protein or antibody in ovarian cancer cells. Besides experiments in vitro, the association between HE4 and P-gp was further studied in human samples. Expression patterns of HE4 and P-gp in drug-resistant and drug-sensitive EOC tissues were assessed via IHC. The potential associations between HE4 or P-gp expression with clinical-pathological parameters and the prognosis of ovarian cancer were confirmed. To further elucidate the underlying mechanisms by which the HE4 regulates drug resistance in ovarian cancer cells, microRNAs (miRNAs/miRs) that bound P-gp gene, ABCB1, were predicted using bioinformatics methods and their expression changes before and after the transfection and exposure to different interventions. In addition, since HE4 may participate in the development of multidrug resistance of $\mathrm{OC}$ at multiple levels, the common signaling pathways shared by HE4, ANXA2 and P-gp were selected using the network database. The present study provides a strong foundation for establishing the role of HE4 in drug resistance of human EOC.

\section{Materials and methods}

Specimen sources. Paraffin specimens of surgical resection from 52 cases of ovarian cancer (33 of low-grade serous carcinoma, 3 of mucinous cystadenocarcinoma, 3 of ovarian endometrioid carcinoma, 2 of ovarian clear cell carcinoma, and 11 of high-grade serous carcinoma), were obtained from the Department of Obstetrics and Gynecology, Shengjing Hospital of China Medical University (Shenyang, China), between 2006 and 2009. All patients with ovarian cancer have not undergone chemotherapy before surgery, and pathology sections were confirmed by experts after hematoxylin and eosin (HE) staining. The classification of the cancer stage was according to the International Federation of Gynecology and Obstetrics (FIGO, 2009) (20). Among the 52 patients with OC, 12 were at FIGO stage I, 5 cases were at FIGO stage II, 34 were at FIGO stage III, and 1 was at FIGO stage IV. All patients were given 6-8 cycles of paclitaxel plus platinum (TC) systemic chemotherapy after surgery according to National Comprehensive Cancer Network (NCCN) guidelines (21) and have accepted regular follow-ups for more than one year after chemotherapy. According to the guideline of NCCN (the chemotherapy resistant group includes patients who had a clinical response to the initial TC chemotherapy program but experienced subsequent relapse, either in the late stage of chemotherapy or within 6 months after the completion of chemotherapy, and the chemotherapy sensitive group includes patients who maintained a clinical response for $\geq 12$ months). The patients were divided into chemotherapy resistant group (23 cases) and sensitive group (29 cases). The age range of the chemosensitive patients was 24 to 78 years (median age, 52 years); The age range of the chemoresistant patients was 34 to 76 years (median age, 54 years). There was no statistically significant difference in age between the chemosensitive and chemoresistant patients.

Cell culture and transfection. All ovarian cancer cell lines (CAOV3, SKOV3 and OVCAR3) were purchased from American Type Culture Collection and cultured in McCoy's 5A modified medium (Gibco; Thermo Fisher Scientific, Inc.) with $10 \%$ fetal bovine serum (Thermo Fisher Scientific, Inc.) at $37^{\circ} \mathrm{C}$ and $5 \% \mathrm{CO}_{2}$. Construction of expression vectors were prepared as previously described (14). The short hairpin RNA (shRNA) expression vectors for human HE4 or ANXA2 were constructed using the pSilencer 4.1-CMV neo vector (Ambion; Thermo Fisher Scientific, Inc.). Cultured CAOV-3 cells were transfected with $3.0 \mu \mathrm{g}$ plasmid according to the manufacturer's instructions of the Lipofectamine ${ }^{\circledR}$ LTX with Plus reagent (Invitrogen; Thermo Fisher Scientific, Inc.). Briefly, $15 \mu 1$ Lipofectamine LTX reagent was diluted in $150 \mu 1$ 
Opti-MEM (Invitrogen; Thermo Fisher Scientific, Inc.), and $16.8 \mu \mathrm{g}$ plasmid was diluted in $700 \mu \mathrm{l}$ Opti-MEM. Then, $150 \mu \mathrm{l}$ diluted Lipofectamine LTX reagent was mixed with $150 \mu \mathrm{l}$ diluted plasmid, and incubated for $5 \mathrm{~min}$ at room temperature. Subsequently, $250 \mu \mathrm{l}$ complex was added to the cells in 6-well plates and the cells were incubated for $48 \mathrm{~h}$ at $37^{\circ} \mathrm{C}$. Stable cell lines CAOV3-HE4-L (expressing HE4 shRNAs) and CAOV3-ANXA2-L (expressing ANXA2 shRNAs) were screened for 14 days with $800 \mu \mathrm{g} / \mathrm{ml} \mathrm{G} 418$ (Invitrogen; Thermo Fisher Scientific, Inc.; cat. no. 11811023), and the mock group was transfected with mock plasmid (empty plasmid). Cells were cultured for a further 10 days and the stable cell lines were used for subsequent experiments. Reagents and transfection procedures were the same as previously described (14).

Western blot analysis (WB). Western blots were prepared as previously described (22). Primary antibodies included: Rabbit anti-human HE4 (1:2,000; Abcam; cat. no. ab109298), mouse anti-human ANXA2 (1:1,000; ProteinTech Group, Inc.; cat. no. 66035-1-Ig), rabbit anti-human P-gp (1:500; Santa Cruz Biotechnology, Inc.; cat. no. sc-8313), and mouse anti-human $\beta$-actin (1:5,000; Beijing Biosynthesis Biotechnology Co., Ltd.; cat. no. bsm-33036M). Goat anti-rabbit or mouse secondary antibodies were used (1:5,000; ZSGB-BIO; cat. nos. ZB-2301 and ZB-2305).

Immunocytochemistry. Monolayer cell slides were prepared from three types of ovarian cancer cells, CAOV3, SKOV3 and OVCAR3, during the exponential growth phase. Reagents were prepared as described for the immunohistochemistry assay (14), and the primary antibody used was rabbit anti-human P-gp (1:200; Santa Cruz Biotechnology, Inc.; cat. no. sc-8313). All procedures were carried out as described on reagent kit instructions. The samples were visualized using an inverted light optical microscope (magnification, x400; Olympus Corporation).

Co-immunoprecipitation. CAOV3 cells were cultured in McCoy's 5A (Hyclone; Cytvia; cat. no. SH30270.01) medium with $10 \%$ fetal bovine serum (Thermo Fisher Scientific, Inc.) albumin medium, and incubated in an incubator at $37^{\circ} \mathrm{C}$ and $5 \% \mathrm{CO}_{2}$. Rabbit anti-human HE4 antibodies (cat. no. ab109298) and rabbit anti-human ANXA2 antibodies (cat. no. ab235939) were purchased from Abcam. Furthermore, goat anti-human HE4 antibodies (cat. no. sc27570), rabbit anti-human P-gp antibodies (cat. no. sc-8313) and mouse anti-human P-gp antibodies (cat. no. sc13131) were purchased from Santa Cruz Biotechnology, Inc. Mouse anti-human ANXA2 antibodies (cat. no. 66035-1-Ig) were purchased from ProteinTech Group, Inc. Details of the experimental procedures were carried out as previously (22). Three co-immunoprecipitations were performed: i) ANXA2 protein was precipitated with mouse anti-human ANXA2 antibodies and detected with rabbit anti-human ANXA2 antibodies, HE4 protein was detected with rabbit anti-human HE4 antibodies, and P-gp protein was detected with rabbit anti-human P-gp antibodies; ii) P-gp protein was precipitated with rabbit anti-human P-gp antibodies and detected with mouse anti-human P-gp antibodies, ANXA2 protein was detected with mouse anti-human ANXA2 antibodies, and HE4 protein was detected with goat anti-human HE4 antibodies; and iii) and HE4 protein was precipitated with rabbit anti-human HE4 antibodies and detected with goat anti-human HE4 antibodies, ANXA2 protein was detected with mouse anti-human ANXA2 antibodies, and P-gp protein was detected with mouse anti-human $\mathrm{P}-\mathrm{gp}$ antibodies. The primary antibody was replaced by rabbit IgG (BIOSS; cat. no. bs-0295P) as a negative control. An enhanced chemiluminescence reagent was used (Amersham ECL Prime Western Blotting Detection reagent; Cytvia; cat. no. RPN2232), and the experiment was repeated three times.

Confocal laser scanning microscopy. Two immunofluorescence double-labeling experiments were carried out. For both, protocols strictly followed the instructions of the reagent suppliers. Firstly, rabbit anti-human HE4 antibodies (1:50; Abcam; cat. no. ab109298) and mouse anti-human P-gp antibodies (1:50; Santa Cruz Biotechnology, Inc.; cat. no. sc13131) were simultaneously incubated on monolayered cell slides prepared from CAOV3 cells. Then, the secondary antibodies were applied: Fluorescein isothiocyanate (FITC) green fluorescence-labeled rabbit IgG fluorescence (1:100; Beijing Zhongshan Jinqiao Biotechnology Co., Ltd.; cat. no. ZF-0314) and tetramethylrhodamine (TRITC) red fluorescence-labeled mouse IgG (1:50; Beijing Zhongshan Jinqiao Biotechnology Co., Ltd.; cat. no. ZF-0316). Cell nuclei were stained with 4',6-diamidino-2-phenylindole (DAPI; Beyotime Institute of Biotechnology; cat. no. C1002). Secondly, mouse anti-human ANXA2 antibodies (1:100; Abcam; cat. no. 66035-1-Ig) and rabbit anti-human $\mathrm{P}-\mathrm{gp}$ antibodies (1:50; Biotechnology, Inc.; cat. no. sc-8313) were simultaneously incubated on monolayered cell slides prepared from CAOV3 cells. After that, the secondary antibodies were applied: FITC green fluorescence-labeled rabbit IgG fluorescence (1:100) and TRITC red fluorescence-labeled mouse IgG (1:50). Cell nuclei were stained with DAPI. Double-labeled immunofluorescence samples were captured by fluorescence confocal microscopy (magnification, $\mathrm{x} 400$ ).

Reverse transcription-quantitative polymerase chain reaction $(R T-q P C R)$. RNA was extracted from pretreated cells with RNAiso Plus reagent (Takara Biotechnology Co., Ltd.) and reverse-transcribed by a Prime-Script RT reagent kit (Takara Biotechnology Co., Ltd.). The reaction conditions for mRNA were $37^{\circ} \mathrm{C}$ for $15 \mathrm{~min}, 85^{\circ} \mathrm{C}$ for $5 \mathrm{sec}, 4^{\circ} \mathrm{C}$ for $5 \mathrm{~min}$; and for miRNA were $37^{\circ} \mathrm{C}$ for $60 \mathrm{~min}, 85^{\circ} \mathrm{C}$ for $5 \mathrm{~min}$. Real-time PCR and $\mathrm{Ct}$ value analysis were performed with a Roche LightCycler system. The primer sequences were as follows: HE4 forward, 5'-CCGACAACCTCAAGTGCTG-3'; HE4 reverse, 5'-CGA GCTGGGGAAAGTTAATG-3'; ANXA2 forward, 5'-TTG CCATTAAACTCACATGAAGTAG-3'; ANXA2 reverse, 5'-GCACAGGATTTCGTGAACAGTAG-3'; P-gp forward, 5'-TGGGGCTGGACTTCCTCTCATGATGC-3'; P-gp reverse, 5'-GCAGCAACCAGCACCCCAGCACCAAT-3'; $\beta$-actin forward, 5'-ACTTAGTTGCGTTACACCCTTTC TTG-3'; $\beta$-actin reverse, 5'-TGTCACCTTCACCGTTCCAGT TTT-3'; hsa-miR-129-5p, 5'-CTTTTTGCGGTCTGGGCT TGC-3'; hsa-miR-4282, 5'-TAAAATTTGCATCCAGGA-3'; hsa-miR-4778-5p, 5'-AATTCTGTAAAGGAAG AAGAGG-3'; hsa-miR-4708-3p, 5'-AGCAAGGCGGCATCTCTCTGAT-3'; hsa-miR-4432, 5'-AAAGACTCTGCAAGATGCCT-3'; RNU6-2 
forward, 5'-CACCACGTTTATACGCCGGGTG-3'; and RNU6-2 reverse, 5'-CTGGTGTCGTGGAGTCGGCAA TTC-3'.

The qPCR amplification conditions were as follows: denaturation at $95^{\circ} \mathrm{C}$ for $30 \mathrm{sec}$, extension at $95^{\circ} \mathrm{C}$ for $5 \mathrm{sec}$, and annealing at $60^{\circ} \mathrm{C}$ for $31 \mathrm{sec}$, total of 40 cycles. The reaction mixture contained SYBR Premix Ex Taq ${ }^{\mathrm{TM}}$ (X2) $10 \mu 1$, PCR Forward Primer (10 $\mu \mathrm{mol} / \mathrm{l}) 0.4 \mu \mathrm{l}$, PCR reverse primer (10 $\mu \mathrm{mol} / \mathrm{l}) 0.4 \mu \mathrm{l}$, cDNA $2 \mu \mathrm{l}$, dH2O $7.2 \mu \mathrm{l}$. $\beta$-actin or RNU6-2 was used as the internal reference. Once the amplification was completed, the melting curve was analyzed. The change of target gene expression level was calculated using the $2^{-\Delta \Delta C q}$ method (23).

MTT assay. All cells were inoculated at 2,000 cells/well in 96-well plates, with a blank well set aside. Increasing doses of adriamycin (Meilun Biotechnology Co., Ltd.; cat. no. MB1087-S) were added after $6 \mathrm{~h}$ of cell culture, and this was regarded as the ' 0 time points'. After $24 \mathrm{~h}$, cell viability assays were performed by adding MTT solution (10 $\mu 1$; $5 \mu \mathrm{g} / \mathrm{ml}$; Beijing Solarbio Science \& Technology Co., Ltd.) and incubated at $37^{\circ} \mathrm{C} / 5 \% \mathrm{CO}_{2}$ for $4 \mathrm{~h}$. The culture medium was removed and $150 \mu 1 \mathrm{DMSO}$ (Beyotime Institute of Biotechnology; cat. no. ST038) was added. After shaking for $10 \mathrm{~min}$, the OD was measured using a universal microplate reader at a wavelength of $490 \mathrm{~nm}$. For each treatment, three parallel wells were settled for statistical analysis. The experiment was repeated three times.

Assessment of P-gp expression on the cell surface. To analyze the P-gp expression level on the cell surface, CAOV3, CAOV3-HE4-L, CAOV3-A2-L, or CAOV3-Mock (empty plasmid control group) cells were digested with $0.25 \%$ trypsin (Gibco; Thermo Fisher Scientific, Inc.; cat. no. 25200-072) and counted. Cells $\left(2 \times 10^{5}\right)$ were rinsed and dissolved with ice-cold PBS containing 1\% BSA (Biological Industries; cat. no. 04-011-1A/B) and incubated with $5 \mu 1$ of the PE-labeled monoclonal anti-(human P-gp) antibody UIC2 (eBioscience; Thermo Fisher Scientific, Inc.; cat. no. 12-2439) at $4^{\circ} \mathrm{C}$ for $30 \mathrm{~min}$ in darkness. Then, cells were washed and resuspended in cold PBS. The binding affinity of the PE-labeled P-gp antibody was measured using flow cytometer.

Measurement of adriamycin accumulation by flow cytometry. CAOV3, CAOV3-HE4-L, CAOV3-A2-L, or CAOV3-Mock (empty plasmid control group) cells were inoculated onto 6 -well plates at a density of $5 \times 10^{5}$ cells per well. After $24 \mathrm{~h}$, the cells were pretreated with complete medium containing or not containing verapamil (50 $\mu \mathrm{M}$; Nanjing SenBeiJia Biological Technology Co., Ltd.; cat. no. 100223) for $1 \mathrm{~h}$. After that, cells were incubated with $10 \mu \mathrm{M}$ adriamycin in culture medium in the dark for $60 \mathrm{~min}$ at $37^{\circ} \mathrm{C}, 5 \% \mathrm{CO}_{2}$. After incubation, the medium was removed, and all monolayers were washed three times with ice-cold PBS. Cells were re-suspended and the fluorescence intensity of intracellular adriamycin was determined by flow cytometry.

Antibody blocking and exogenous active protein supplementation tests. CAOV3 or CAOV3-A2-L cells during the log phase were selected and single-cell suspensions were prepared. The dialysis membrane with medium-length molecular retention of $10 \mathrm{kDa}$ was used to remove sodium azide from the antibodies. IgG (BIOSS; cat. no. bs-0295P), HE4 exogenous active protein $(100 \mathrm{ng} / \mathrm{ml}$; Novoprotein; cat. no. C550A), ANXA2 exogenous active protein $(10 \mathrm{ng} / \mathrm{ml}$; Novoprotein; cat. no. C205A), HE4 antibodies $(10 \mu \mathrm{g} / \mathrm{ml}$; Abcam; cat. no. ab109298), ANXA2 antibodies (10 $\mu \mathrm{g} / \mathrm{ml}$; ProteinTech Group, Inc.; cat. no. 66035-1-Ig), or ANXA2 antibodies $(10 \mu \mathrm{g} / \mathrm{ml}$; ProteinTech Group, Inc.; cat. no. 66035-1-Ig) with HE4 exogenous active protein, was added to the adherent cells. The cells were incubated at $37^{\circ} \mathrm{C}$ for 0,12 and $24 \mathrm{~h}$, and then the protein and mRNA were extracted for analysis. The experiments were repeated three times and the average value was calculated.

$I H C$. The expression of HE4 and P-gp was detected using streptavidin-peroxidase (SP) and Strept Avidin-Biotin Complex (SABC) IHC staining, using rabbit anti-human HE4 antibodies (1:40; Abcam; cat. no. ab109298) and rabbit anti-human P-gp antigen antibodies (1:50; Santa Cruz Biotechnology, Inc.; cat. no. sc-8313). All other reagents were provided by the central laboratory of Shengjing Hospital of China Medical University. Each experiment included low-grade serous carcinoma, mucinous cystadenocarcinoma, endometrioid carcinoma, clear cell carcinoma, and high-grade serous carcinoma), as well as both positive and negative control sections. The positive control sections for HE4 were epididymal carcinoma tissues, and for $\mathrm{P}$-gp, were P-gp positive colon carcinoma tissues. For negative controls, PBS was substituted for primary antibodies. Staining protocols followed the manufacturer's instructions for the reagent kit as previously described (24).

Immunohistochemistry results were interpreted as previously described (21). Samples were marked positive when the cell membrane or cytoplasm appeared brown or yellow. The $52 \mathrm{OC}$ samples were separated into high expression $(++/+++)$ and low expression (-/+) groups according to levels of HE4 and P-gp staining. Each sample was independently assessed by two people, and by a third person when inconsistencies arose.

Bioinformatics methods of predicting miRNAs that bound to the $P$-gp gene, $A B C B 1$. Four major miRNA predictive analysis tools, miRanda (http://www.microrna.org/microrna/home.do), TargetScan (http://www.targetscan.org), DIANA (http://www. microrna.gr) and miRDB (http://www.mirdb.org/miRDB) were used to predict the miRNAs that bound to the P-gp gene, ABCB1.

Data collection from The Cancer Genome Atlas (TCGA) database and Gene Set Enrichment Analysis (GSEA). Ovarian cancer data was downloaded from GDC Application Programming Interface (API; https://gdc.cancer. gov/developers/gdc-application-programming-interface-api) and prescreened, and 374 tumor samples were included in the present study. Samples were sorted according to the expression level of HE4, ANXA2 or ABCB1, from low to high, and equally aliquoted into four parts: The first $25 \%$ of the samples were the low expression group; the last $25 \%$ of samples were the high expression group. GSEA 3.0 (https://www.gsea-msigdb. org/gsea/msigdb/index.jsp) was used to analyze data. C2.cp. kegg.v6.1.symbols.gmt data cluster was downloaded from 
A

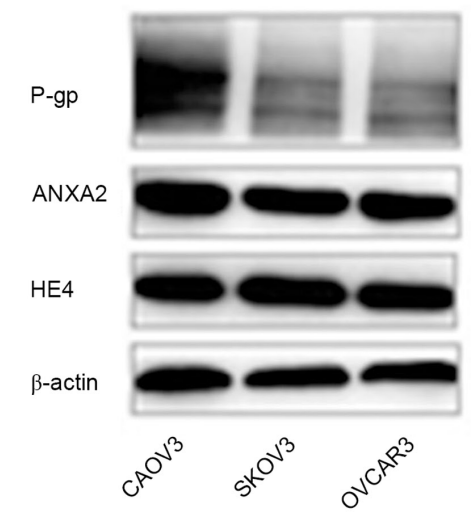

B

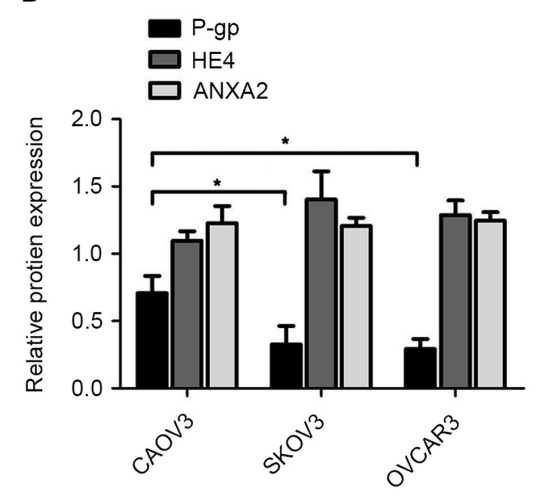

C
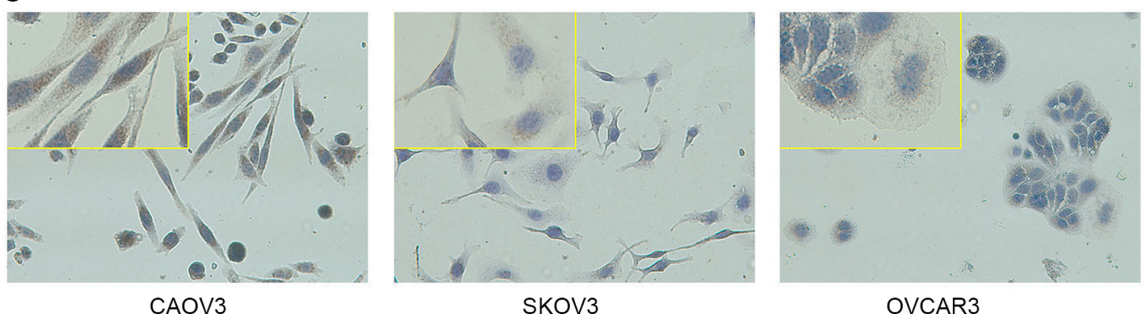

Figure 1. Expression of HE4, ANXA2 and P-gp in ovarian cancer cells (CAOV3, SKOV3 and OVCAR3). (A) Western blot analysis of HE4, ANXA2 and P-gp expression in three cell lines. (B) Comparison of HE4, ANXA2 and P-gp protein levels in three cell lines. (C) Immunocytochemistry detection of P-gp expression in three cell lines. Magnification, $\mathrm{x} 400 .{ }^{*} \mathrm{P}<0.05$. HE4; human epididymis protein 4; P-gp, P-glycoprotein

the Molecular Signatures Database data bank on the GSEA website. Enrichment analysis was performed on the sorted samples using default weighted enrichment statistics. Random assortment times were set to 1,000. For GSEA analysis, gene clusters with false discovery rates (FDR) $<0.25$ and $\mathrm{P}<0.05$ were considered as significantly enriched genes.

Statistical analysis. SPSS 21.0 software (IBM Corp.) was used for statistical analysis, with all data represented by the mean \pm standard deviation. $\chi^{2}$ test, the one-way ANOVA and two-way ANOVA tests followed by a Tukey's post hoc test were employed. Correlated factors were analyzed with multivariate logistic regression and their associations were analyzed with Fisher's exact test. Prognosis and overall survival were analyzed with the multivariate logistic regression, Kaplan-Meier survival analysis and a log-rank test. $\mathrm{P}<0.05$ was considered to indicate a statistically significant difference.

\section{Results}

Expression patterns of HE4, ANXA2 and P-gp in different $O C$ cell lines. In order to study the role of HE4, ANXA2 and P-gp in drug resistance of $\mathrm{OC}$, the expression of HE4, ANXA2 and $\mathrm{P}$-gp were firstly detected in three OC cell lines. The results of WB showed that HE4 and ANXA2 were highly expressed and there was no significant difference among the CAOV3, SKOV3 and OVCAR3 cell lines (Fig. 1A and B). Both WB and immunocytochemistry experiments suggested greater P-gp expression in CAOV3 compared with OVCAR3 and SKOV3 cells (Fig. 1). The average optical densities of ICC were measured under a microscope with image processing, and are presented as the mean \pm standard deviation of three separate experiments, and the results were statistically significant $(\mathrm{P}<0.05$; Table I). The forementioned results suggested that HE4, ANXA2 and P-gp were widely expressed in OC cell lines, and CAOV3 with the highest P-gp expression was used for further experiments.

Interaction of HE4, ANXA2 and P-gp in CAOV3 cells. The associations among HE4, ANXA2 and P-gp were investigated in CAOV3. Co-expression of HE4 and ANXA2, as well as P-gp and ANXA2, were detected via immunoprecipitation analysis. No direct interactions between HE4 and P-gp were detected (Fig. 2A). Colocalization patterns of HE4, ANXA2 and P-gp in CAOV3 cells were assessed via double-labeling immunofluorescence confocal experiment. HE4 labeled with green fluorescence was mainly localized in the cell membrane and cytoplasm, similar to red fluorescence-labeled P-gp, red fluorescence-labeled ANXA2 and green fluorescence-labeled P-gp. Blue fluorescence represents DAPI staining of nuclei. Yellow fluorescence from the overlapping of red and green fluorescence confirmed the colocalization of HE4 or ANXA2 with P-gp (Fig. 2B). Although no direct interactions were detected between HE4 and P-gp via immunoprecipitation analyses, colocalization of HE4/P-gp and ANXA2/P-gp was determined via immunofluorescent staining, indicative of interactions between HE4-ANXA2 complex and P-gp.

Interactions between HE4 and ANXA2 enhances P-gp expression and promotes resistance to adriamycin in CAOV3 cells. In order to further explore whether HE4 affects $\mathrm{P}$-gp-mediated drug resistance in $\mathrm{OC}$ and whether the effects require the involvement of ANXA2, stably transfected cell lines with low expression of HE4 (CAOV3-HE4-L) and ANXA2 (CAOV3-A2-L), respectively, were constructed. WB 
Table I. Average optical densities of immunocytochemistry in different groups.

\begin{tabular}{lc}
\hline Cell lines & Integrated optical density \\
\hline CAOV3 & $15.261 \pm 0.421^{\mathrm{a}, \mathrm{b}}$ \\
SKOV3 & $5.698 \pm 0.499$ \\
OVCAR3 & $7.619 \pm 0.787$ \\
\hline
\end{tabular}

${ }^{\mathrm{a}} \mathrm{P}<0.05$ vs. SKOV $3 ;{ }^{\mathrm{b}} \mathrm{P}<0.05$ vs. OVCAR3.

Table II. $\mathrm{IC}_{50}$ of adriamycin in different groups.

\begin{tabular}{ll}
\hline Cell lines & $\mathrm{IC}_{50}, \mu \mathrm{g} / \mathrm{ml}$ \\
\hline CAOV3 & $4.36 \pm 0.433^{\mathrm{a}, \mathrm{b}}$ \\
CAOV3-Mock & $4.29 \pm 0.366^{\mathrm{a}, \mathrm{b}}$ \\
CAOV3-HE4-L & $2.18 \pm 0.166$ \\
CAOV3-A2-L & $1.72 \pm 0.238$ \\
\hline
\end{tabular}

${ }^{\mathrm{a}} \mathrm{P}<0.01$ vs. CAOV3-HE4-L; ${ }^{\mathrm{b}}<<0.01$ vs. CAOV3-A2-L. HE4; human epididymis protein 4.

Table III. Expression intensity of HE4 and P-gp in different groups.

\begin{tabular}{lcc}
\hline Groups & HE4 & P-gp \\
\hline Resistance group & $0.2642 \pm 1.2220$ & $0.2608 \pm 0.09394$ \\
Sensitive group & $0.1920 \pm 0.9621$ & $0.2088 \pm 0.8579$ \\
P-value & $0.025^{\mathrm{a}}$ & $0.043^{\mathrm{a}}$ \\
\hline
\end{tabular}

${ }^{\mathrm{a}}$-test. HE4; human epididymis protein 4; P-gp, P-glycoprotein.

and RT-qPCR assays confirmed decreased HE4 expression in CAOV3-HE4-L, as well as decreased ANXA2 expression in CAOV3-A2-L cells, both accompanied with decreased $\mathrm{P}$-gp expression in protein and mRNA levels (Fig. 3A-C). Compared with the untreated (CAOV3) and mock groups (CAOV3-Mock; empty plasmid control group), MTT assay showed a significant increase in the proliferation inhibition rate and decrease in $\mathrm{IC}_{50}$ value in CAOV3-HE4-L and CAOV3-A2-L cells $24 \mathrm{~h}$ after adriamycin treatment $(\mathrm{P}<0.05$; Fig. 3D; Table II). Flow cytometry data showed a significant decrease in $\mathrm{P}$-gp expression on the cell membrane in CAOV3-HE4-L and CAOV3-A2-L cells ( $\mathrm{P}<0.05$; Fig. 3E). Simultaneously, intracellular drug accumulation after $1 \mathrm{~h}$ adriamycin treatment was greater in CAOV3-HE4-L and CAOV3-A2-L compared with CAOV3 and CAOV3-Mock (empty plasmid control group) cells (Fig. 3G). Upon pre-treatment of cells with $50 \mu \mathrm{M}$ verapamil (VER), a specific $\mathrm{P}$-gp inhibitor, intracellular adriamycin accumulation in CAOV3 and CAOV3-Mock (empty plasmid control group) cells was markedly increased, compared with that in
A
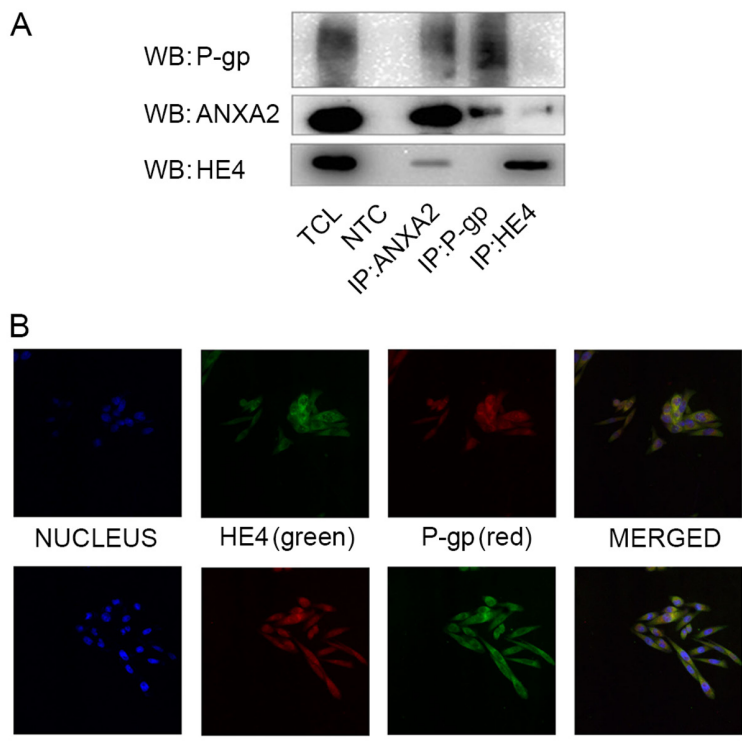

HE4 (green)

P-gp (red)

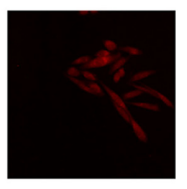

ANXA2(red)

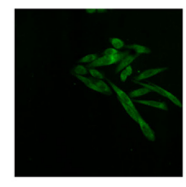

P-gp(green)

MERGED

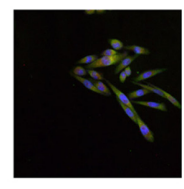

MERGED

Figure 2. Interaction of HE4, ANXA2 and P-gp in CAOV3 cells. (A) Protein lysates of CAOV3 cells were precipitated using HE4, ANXA2 and P-gp-specific antibodies. WB revealed co-expression of HE4 with ANXA2, and ANXA2 with P-gp, respectively. (B) Double-labeling immunofluorescence showed the colocalization of HE4 or ANXA2 with P-gp in CAOV3 cells. Magnification, x400. HE4; human epididymis protein 4; P-gp, P-glycoprotein; WB, western blotting; TCL, total cell lysate; NTC, negative control, the primary antibody was replaced by rabbit IgG; IP, immunoprecipitate.

untreated cells (all $\mathrm{P}<0.05$; Fig. 3F and G). However, VER exerted no significant effects on adriamycin accumulation in CAOV3-HE4-L and CAOV3-A2-L cells (Fig. 3F and G). The aforementioned results suggest that drug resistance to adriamycin and the expression and activity of P-gp were significantly decreased accompanied by decreased HE4 or ANXA2 expression after transfection in CAOV3 cells (Fig. 3A-G). WB and RT-qPCR assays confirmed increased $\mathrm{P}$-gp protein and mRNA expression in CAOV3 cells treated with HE4 active protein (group 2) or ANXA2 active protein (group 3), and decreased P-gp expression in CAOV3 cells treated with HE4 antibody (group 4) or ANXA2 antibody (group 5) within $24 \mathrm{~h}$ (Fig. 3H-J). In addition, combined treatment with ANXA2 antibody and active HE4 protein (group 6) resulted in a significant decrease in $\mathrm{P}-\mathrm{gp}$ protein and mRNA levels in CAOV3 cells within $24 \mathrm{~h}($ all $\mathrm{P}<0.05)$ However, $\mathrm{P}-\mathrm{gp}$ protein and mRNA expression patterns in CAOV3-A2-L cells treated with exogenous active HE4 protein were not rescued within $24 \mathrm{~h}$ (group 8) ( $\mathrm{P}>0.05)$. P-gp protein and mRNA expression in untreated CAOV3 cells (group 1), untreated CAOV3-A2-L cells (group 7) and cells treated with IgG (group 9) were not significantly altered across the $24 \mathrm{~h}$ time point $(\mathrm{P}>0.05$; Fig. $3 \mathrm{H}-\mathrm{J})$. These results showed that the expression and activity of P-gp were associated with HE4, which may require the involvement of ANXA2.

Expression of HE4 and P-gp in OC tissues from different groups. Besides experiments in vitro the association between HE4 and P-gp was further studied in human samples. HE4 staining was mainly detected in the cell membrane and cytoplasm in all 52 cases of malignant ovarian tumors. 
A

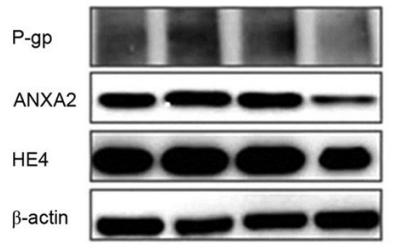

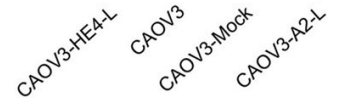

E

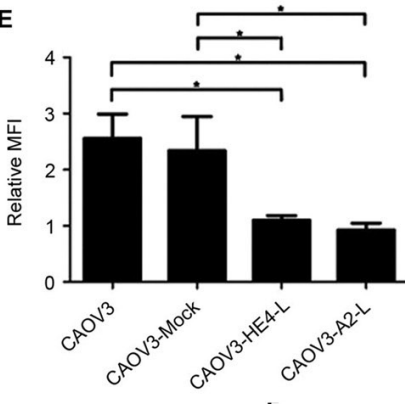

B

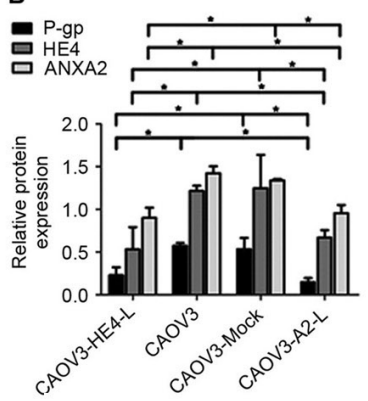

F
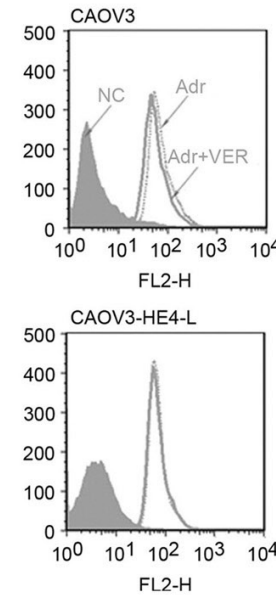

C

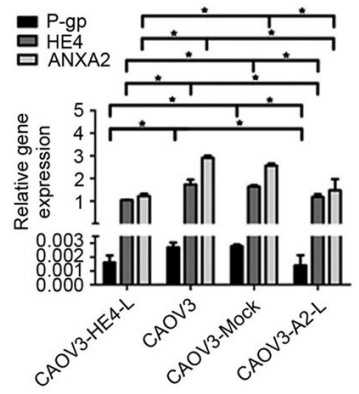

D

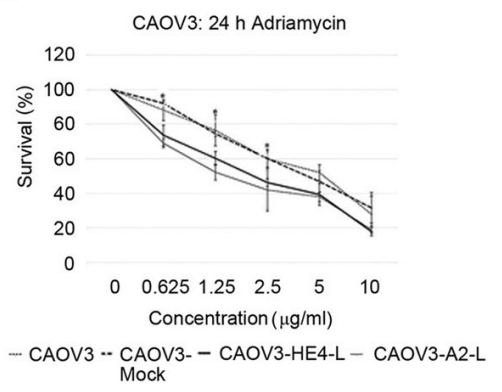

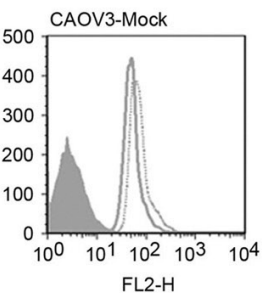

G

口 Adr

Adr+VER

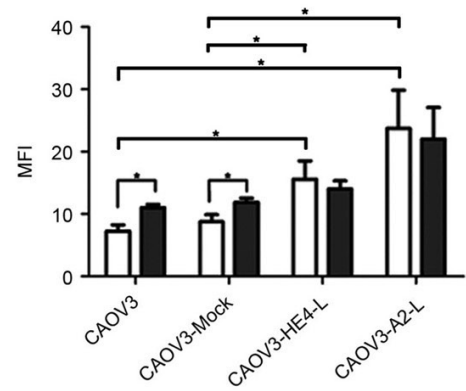

H

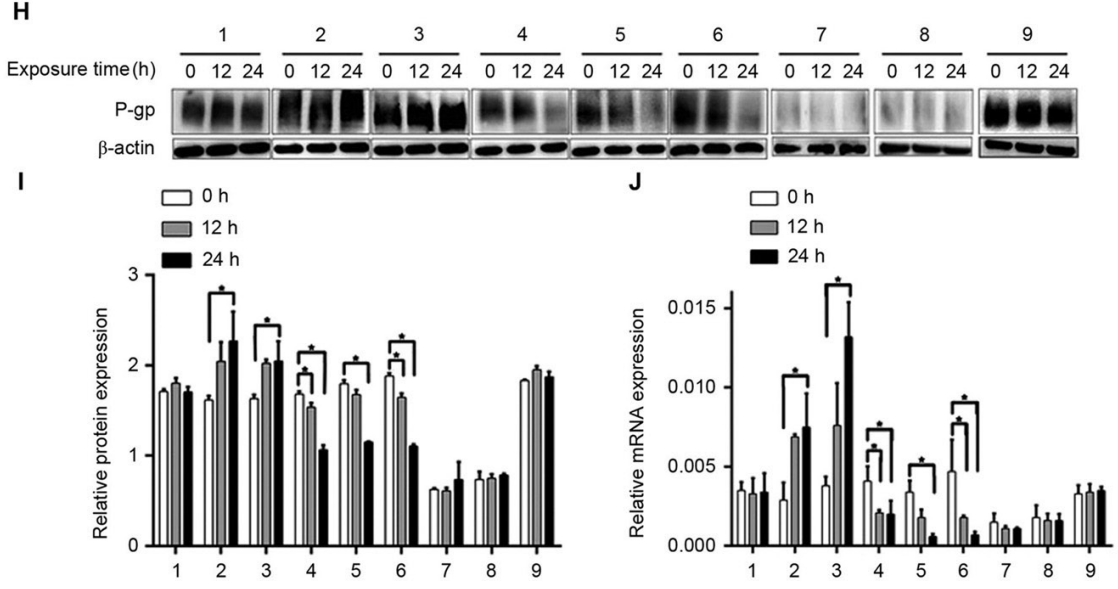

Figure 3. Interaction of HE4 with ANXA2 enhances P-gp expression and promotes resistance to adriamycin in CAOV3 cells. (A) Expression of HE4, ANXA2 and P-gp before and after transfection, detected by western blotting. (B) Comparison of HE4, ANXA2 and P-gp protein levels before and after transfection. (C) Expression of HE4, ANXA2 and P-gp before and after transfection, detected by RT-qPCR assays. (D) Cells were treated with $0-10 \mu \mathrm{g} / \mathrm{ml}$ adriamycin for $24 \mathrm{~h}$ before and after transfection, at which time the cells were subjected to MTT assay to measure viability. Results are displayed as percent survival of vehicle-treated cells. Error bars represent the standard deviation of biological replicates. (E) Flow cytometry detection of the expression of P-gp on the cell membrane before and after transfection. (F) Measurement of adriamycin accumulation by flow cytometry before and after transfection, cells of different groups were pretreated with complete medium containing or not containing verapamil $(50 \mu \mathrm{M})$ for $1 \mathrm{~h}$. After pretreatment, cells were incubated with adriamycin in culture medium. (G) Measurement of MFI of adriamycin by flow cytometry in cells before and after transfection. (H) Expression of P-gp in cells before and after treatment by different antibodies or active protein at different time points, detected by western blotting. Group 1, CAOV3 cells; group 2, CAOV3 cells treated with HE4 active protein; group 3, CAOV3 cells treated with ANXA2 active protein; group 4, CAOV3 cells treated with HE4 antibody; group 5, CAOV3 cells treated with ANXA2 antibody; group 6, CAOV3 cells treated with HE4 active protein and ANXA2 antibody; group 7, CAOV3-A2-L cells; group 8, CAOV3-A2-L cells treated with HE4 active protein; and group 9, CAOV3 cells treated with IgG. (I) Comparison of P-gp protein levels before and after treatment by different antibodies or active protein at different time points. The cells of each group were treated as same as (H). (J) Expression of P-gp in cells before and after treatment by different antibodies or active protein at different time points, detected by RT-qPCR assays. The cells of each group were treated as same as $(\mathrm{H})$. "P<0.05. HE4; human epididymis protein 4; P-gp, P-glycoprotein; RT-qPCR, reverse transcription-quantitative polymerase chain reaction; MFI, mean fluorescence intensity; VER, verapamil.

The positive rate of HE4 from the drug-resistant group was $95.65 \%$, which was significantly higher than that $(65.51 \%)$ of the drug-sensitive group. Additionally, the expression level intensity of HE4 of the drug-resistant group was significantly higher compared with that of the drug-sensitive group. In the drug-resistant group, 17 cases showed strong positive HE4 
Table IV. Expression of HE4 in different groups.

\begin{tabular}{lcrrrrrrrr}
\hline Groups & Cases & - & + & ++ & +++ & $\begin{array}{c}\text { High } \\
\text { expression } \\
\text { cases, } n\end{array}$ & $\begin{array}{c}\text { High } \\
\text { expression } \\
\text { rate, } \%\end{array}$ & $\begin{array}{c}\text { Positive } \\
\text { cases, } n\end{array}$ & $\begin{array}{c}\text { Positive } \\
\text { rate, } \%\end{array}$ \\
\hline Resistance group & 23 & 1 & 5 & 5 & 12 & 17 & 73.91 & 22 & 95.65 \\
Sensitive group & 29 & 10 & 11 & 5 & 3 & 8 & 27.59 & 19 & 65.51 \\
\hline
\end{tabular}

Table V. Expression of P-glycoprotein in different groups.

\begin{tabular}{|c|c|c|c|c|c|c|c|c|c|}
\hline Groups & Cases & - & + & ++ & +++ & $\begin{array}{l}\text { High } \\
\text { expression } \\
\text { cases, } \mathrm{n}\end{array}$ & $\begin{array}{l}\text { High } \\
\text { expression } \\
\text { rate, } \%\end{array}$ & $\begin{array}{l}\text { Positive } \\
\text { cases, } n\end{array}$ & $\begin{array}{c}\text { Positive } \\
\text { rate, } \%\end{array}$ \\
\hline Resistance group & 23 & 1 & 4 & 8 & 10 & 18 & 78.26 & 22 & 95.65 \\
\hline Sensitive group & 29 & 7 & 10 & 9 & 3 & 12 & 41.37 & 22 & 75.86 \\
\hline
\end{tabular}
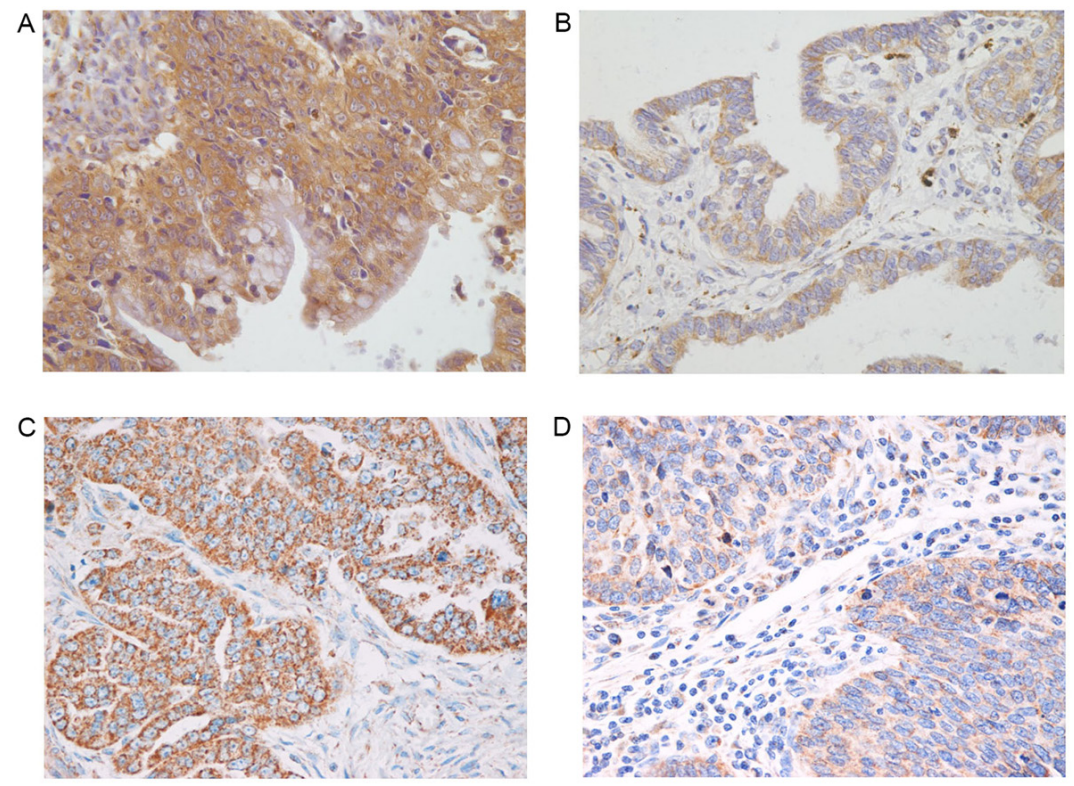

Figure 4. Expression of HE4 and P-gp in ovarian cancer tissue. IHC to detect the expression of HE4 in (A) the resistant group and (B) the sensitive group. IHC to detect the expression of P-gp in (C) the resistant group and (D) in the sensitive group. Magnification, x400. HE4; human epididymis protein 4; P-gp, P-glycoprotein; IHC, immunohistochemistry.

staining $(73.91 \%)$, while there were only 8 cases with strong positive HE4 staining in the drug-sensitive group (All $\mathrm{P}<0.05$; Fig. 4A and B; Tables III and IV).

$\mathrm{P}$-gp staining was also mainly detected in the cell membrane and cytoplasm. The percentage of positively stained samples was significantly higher in the drug-resistant group compared with that of drug-sensitive group (95.65 vs. $75.86 \%$ ). Moreover, the expression intensity of P-gp in the drug-resistant group was significantly higher compared with that of the drug-sensitive group. In the drug-resistant group, 18 patients showed strong positive staining $(78.26 \%)$. In the drug-sensitive group, strong positive staining was only detected in 12 cases (All $\mathrm{P}<0.05$; Fig. 4C and D; Tables III and V).
Association between expression of HE4 and P-gp with clinical pathological-parameters. Expression patterns of HE4 were similar to those of P-gp. The high expression rate of HE4 in the late stages group of FIGO was $57.14 \%$, which was higher than that of the early stages $(29.41 \%)$; and the lymph node metastasis group (60\%) was higher than that of the non-lymph node metastasis group (36\%) $(\mathrm{P}>0.05)$. The high expression rate of $\mathrm{HE} 4$ in the postoperative residual tumor $\geq 1 \mathrm{~cm}$ group $(52.63 \%)$ was higher than that of the residual tumor $<1 \mathrm{~cm}$ group (45.45\%), although this difference was not statistically significant $(\mathrm{P}>0.05$; Table VI).

The high expression rate of $\mathrm{P}$-gp was $65.71 \%$ in the late stages (FIGO stage III/IV) relative to $41.18 \%$ in the early 
Table VI. Expression of HE4 and P-gp in ovarian cancer tissue.

\begin{tabular}{|c|c|c|c|c|c|c|c|}
\hline \multirow[b]{2}{*}{ Characteristics } & \multirow[b]{2}{*}{ Cases } & \multicolumn{2}{|c|}{ HE4 } & \multirow[b]{2}{*}{ P-value } & \multicolumn{2}{|c|}{ P-gp } & \multirow[b]{2}{*}{ P-value } \\
\hline & & High, $\mathrm{n}$ & $\%$ & & High, n & $\%$ & \\
\hline FIGO stage & & & & 0.060 & & & 0.093 \\
\hline I-II & 17 & 5 & 29.41 & & 7 & 41.18 & \\
\hline III-IV & 35 & 20 & 57.14 & & 23 & 65.71 & \\
\hline Lymph node metastasis & & & & 0.317 & & & 0.317 \\
\hline Yes & 5 & 3 & 60 & & 4 & 80 & \\
\hline No & 25 & 9 & 36 & & 14 & 56 & \\
\hline Histologic subtype & & & & 0.051 & & & 0.904 \\
\hline Low-grade serous carcinoma & 33 & 20 & 60.61 & & 20 & 60.61 & \\
\hline Mucinous cystadenocarcinoma & 3 & 1 & 33.33 & & 1 & 33.33 & \\
\hline Endometrioid carcinoma & 3 & 0 & 0 & & 2 & 66.67 & \\
\hline Clear cell carcinoma & 2 & 0 & 0 & & 1 & 50 & \\
\hline High-grade serous carcinoma & 11 & 3 & 27.27 & & 6 & 54.55 & \\
\hline Postoperative residual lesions & & & & 0.618 & & & 0.235 \\
\hline$<1 \mathrm{~cm}$ & 33 & 15 & 45.45 & & 17 & 51.51 & \\
\hline$\geq 1 \mathrm{~cm}$ & 19 & 10 & 52.63 & & 13 & 68.42 & \\
\hline
\end{tabular}

HE4; human epididymis protein 4; P-gp, P-glycoprotein.

Table VII. Association between HE4 and P-gp expression.

\begin{tabular}{lccc}
\hline & & \multicolumn{2}{c}{ P-gp } \\
\cline { 3 - 4 } HE4 & Cases, $n$ & Negative, $n$ & Positive, $n$ \\
\hline Negative & 10 & 5 & 5 \\
Positive & 42 & 4 & 38 \\
Total cases & 52 & 9 & 43 \\
\hline
\end{tabular}

HE4; human epididymis protein 4; P-gp, P-glycoprotein.

stages (FIGO stage I/II), 80.0\% (4/5) in the lymph node metastasis group relative to the non-lymph node metastasis group $(56 \%)$, and $68.42 \%$ in the residual tumor $\geq 1 \mathrm{~cm}$ group relative to the residual tumor $<1 \mathrm{~cm}$ group (51.51\%). However, these differences were not statistically significant (all $\mathrm{P}>0.05$; Table VI).

Associations between HE4 and P-gp expression in OC tissues. Among 52 OC tissue cases, 38 showed double-positive staining for HE4 and P-gp, while 5 cases showed that neither existed. Cases with highly expressed HE4 concomitantly showed high P-gp expression, suggesting associations between the two proteins $(\mathrm{P}=0.008$; Table VII).

Associations of $\mathrm{P}-\mathrm{gp}$ and HE4 expression with prognosis. Multiple factors logistic regression analysis was carried out. FIGO stage, residual tumor volume, drug resistance and expression of HE4 and P-gp were used as dependent variables. The analysis revealed that FIGO stage III-IV and high expression of HE4 and P-gp were independent risk factors for poor prognosis of epithelial ovarian cancer (Table VIII).

Survival analysis. Among the 52 cases of ovarian cancer, 43 were followed up and 9 were lost (until May 2015). The results of Kaplan-Meier and log-rank tests showed significantly higher mortality in HE4 and P-gp high expression, late FIGO stage (III-IV) and drug-resistant groups compared with that in HE4 and P-gp low expression, early FIGO stage (I-II) and chemotherapy-sensitive groups, respectively (Fig. 5).

Prediction of miRNAs regulating the 3'-UTR of ABCB1. Furthermore, in order to elucidate the detailed mechanisms by which the HE4-ANXA2 complex regulates P-gp-mediated drug resistance in OC cells, miRNAs that bound the P-gp gene, ABCB1, were predicted using bioinformatics methods. The number of miRNAs with the potential to bind the 3'-UTR region of $\mathrm{ABCB} 1$ was 14, 376, 26 and 13, respectively, as predicted by different algorithms of the four databases. Five miRNAs were intersected by three of the four websites, specifically, hsa-miR-129-5p, hsa-miR-4282, hsa-miR-4778-5p, hsa-miR-4708-3p and hsa-miR-4432 (Fig. 6).

Inhibitory regulation of hsa-miR-129-5p by HE4 via interactions with ANXA2. RT-qPCR was then employed to investigate the associations among HE4, ANXA2 and the five miRNAs in CAOV3-HE4-L and CAOV3-A2-L cells. Data from a RT-qPCR assay showed increased expression of hsa-miR-129-5p in both CAOV3-HE4-L and CAOV3-A2-L cells, compared with CAOV3 and CAOV3-Mock group (empty plasmid control group), while no significant differences in hsa-miR-4708-3p 
Table VIII. Ovarian cancer prognostic multi-factor analysis.

\begin{tabular}{|c|c|c|c|c|c|c|c|}
\hline Variables & $B$ & $S E$ & Wald & $d f$ & P-value & $O R$ & $95.0 \% C I$ \\
\hline HE4 & 1.022 & 0.360 & 8.058 & 1 & 0.005 & 2.780 & $1.372 \sim 5.632$ \\
\hline P-gp & 0.945 & 0.357 & 7.003 & 1 & 0.008 & 2.572 & $1.278 \sim 5.177$ \\
\hline Surgical stage & 1.085 & 0.451 & 5.774 & 1 & 0.016 & 2.958 & $1.221 \sim 7.164$ \\
\hline Postoperative residual lesions & 0.024 & 0.420 & 0.003 & 1 & 0.954 & 1.024 & $0.450 \sim 2.333$ \\
\hline Drug resistance & 0.598 & 0.531 & 1.268 & 1 & 0.260 & 1.819 & $0.642 \sim 5.150$ \\
\hline
\end{tabular}

HE4; human epididymis protein 4; P-gp, P-glycoprotein.
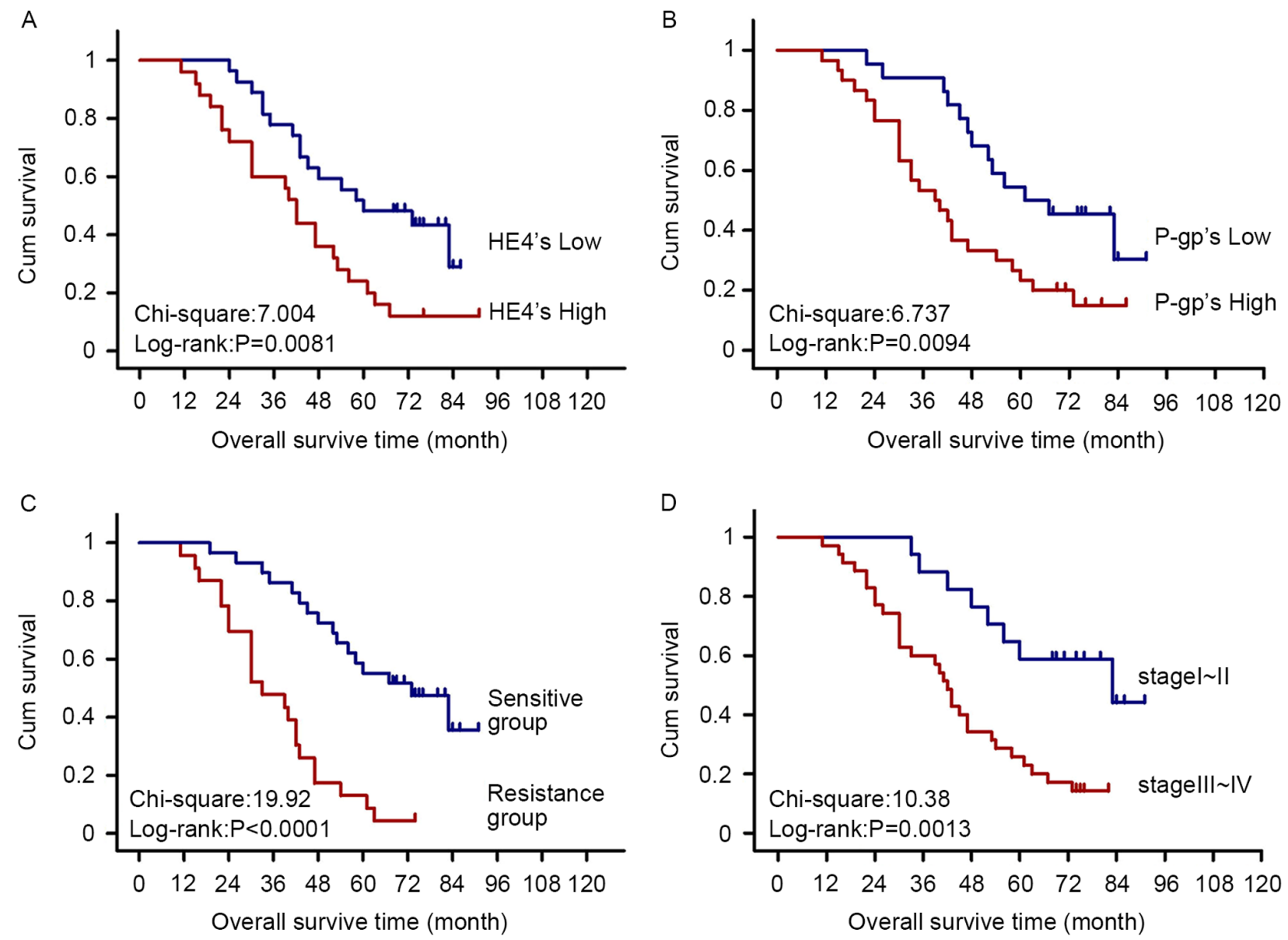

Figure 5. The association between HE4 expression, P-gp expression, drug resistance or FIGO stage and survival time of patients with ovarian cancer. Kaplan-Meier survival analysis showed that a (A) high expression of HE4, (B) high expressions of P-gp, (C) drug resistance, (D) late FIGO stage were independent risk factors for overall survival. HE4; human epididymis protein 4; P-gp, P-glycoprotein; FIGO, Federation of Gynecology and Obstetrics; Cum survival, cumulative survival.

expression were observed. Levels of hsa-miR-4282 and hsa-miR-4778-5p were slightly decreased in CAOV3-HE4-L and CAOV3-A2-L cells, but these differences were not significant. The expression of hsa-miR-4432 remained constant in CAOV3-HE4-L cells but increased in CAOV3-A2-L cells, albeit not to a significant extent (Fig. 7A). Among the five miRNAs, only hsa-miR-129-5p was significantly increased, accompanied by decreased HE4 or ANXA2 expression and $\mathrm{P}$-gp expression in CAOV3-HE4-L and CAOV3-A2-L cells, indicating that the expression of hsa-miR-129-5p is consistent with those of HE4, ANXA2 and P-gp. CAOV3 cells were then treated with $\operatorname{IgG}$, exogenous active HE4, exogenous active ANXA2, HE4 antibody, ANXA2 antibody or exogenous active HE4 protein with ANXA2 antibody. CAOV3-A2-L cells were additionally treated with exogenous active HE4 protein for 0,12 and $24 \mathrm{~h}$. Treatment with exogenous active HE4 or ANXA2 led to a significant decrease in hsa-miR-129-5p expression in CAOV3 cells within $24 \mathrm{~h}$, while treatment with HE4 antibody, ANXA2 antibody and ANXA2 antibody with HE4 active protein induced a significant increase in hsa-miR-129-5p. In CAOV3-A2-L cells, high expression of hsa-miR-129-5p was not reversed within $24 \mathrm{~h}$ after treatment 
A

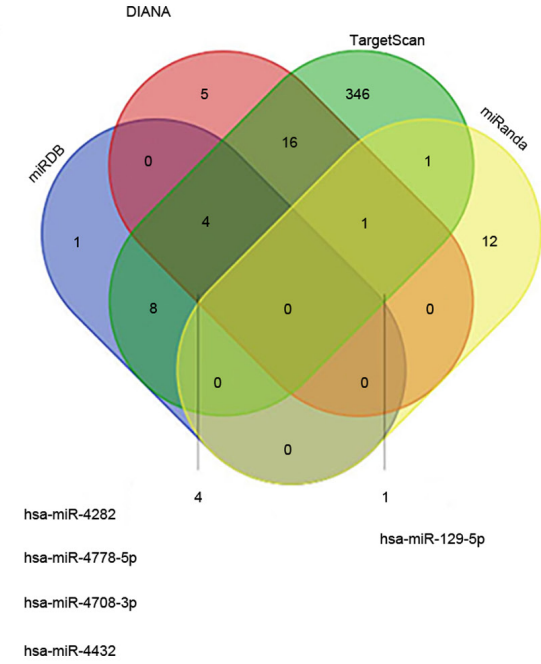

B

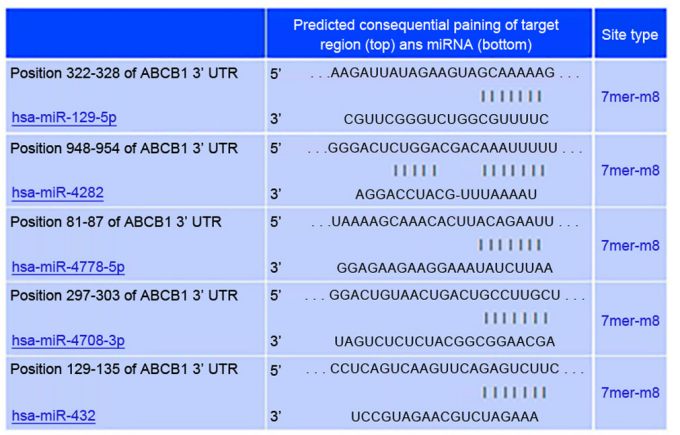

Figure 6. Prediction of miRNAs regulating the 3'URT region of ABCB1. (A) Venn diagram depicting the number of predicted miRNAs of ABCB1 from miRanda, TargetScan, DIANA and miRDB. The overlaps indicate the numbers of miRNAs predicted by more than one algorithm. miRanda, TargetScan, DIANA and miRDB predicted a total of 14, 376, 26, and 13 microRNAs, respectively. (B) TargetScan was used to predict the interaction between miRNAs and 3'URT region of ABCB1. microRNA/miR, microRNAs; UTR, untranslated region.

A

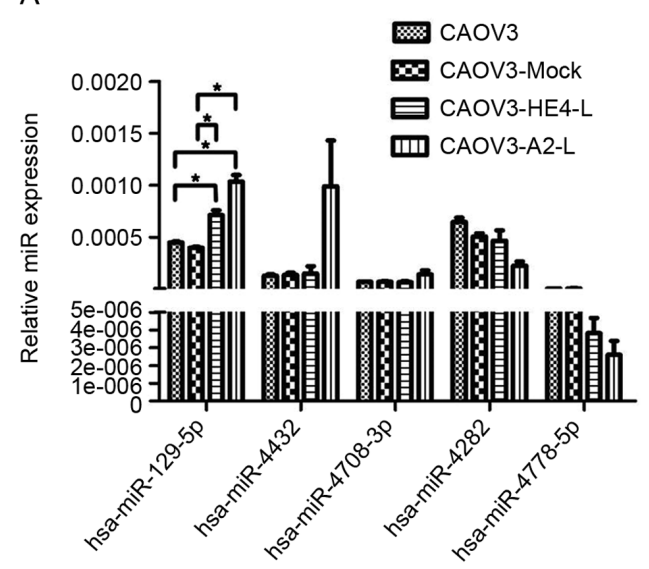

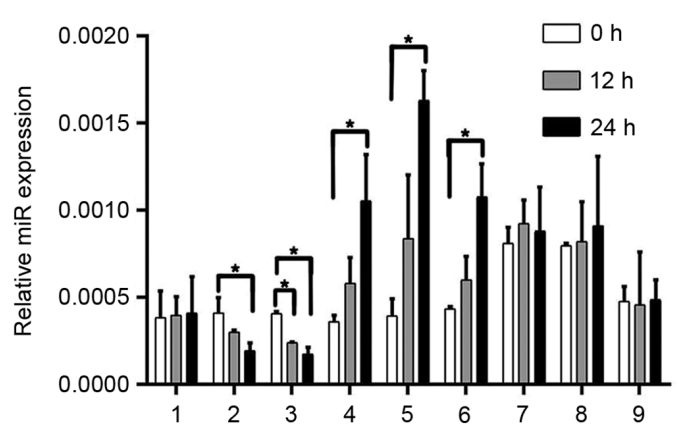

Figure 7. Inhibitory regulation of hsa-miR-129-5p by HE4 via interactions with ANXA2. (A) Expression of five miRNAs expression before and after transfection, detected by reverse transcription-quantitative polymerase chain reaction assays. (B) Expression of hsa-miR-129-5p in cells before and after treatment by different antibodies or active protein at different time points. The cells of each group were treated as same as described for Fig. $3 \mathrm{H}$. ${ }^{*} \mathrm{P}<0.05$. HE4; human epididymis protein 4 ; microRNA/miR, microRNAs.

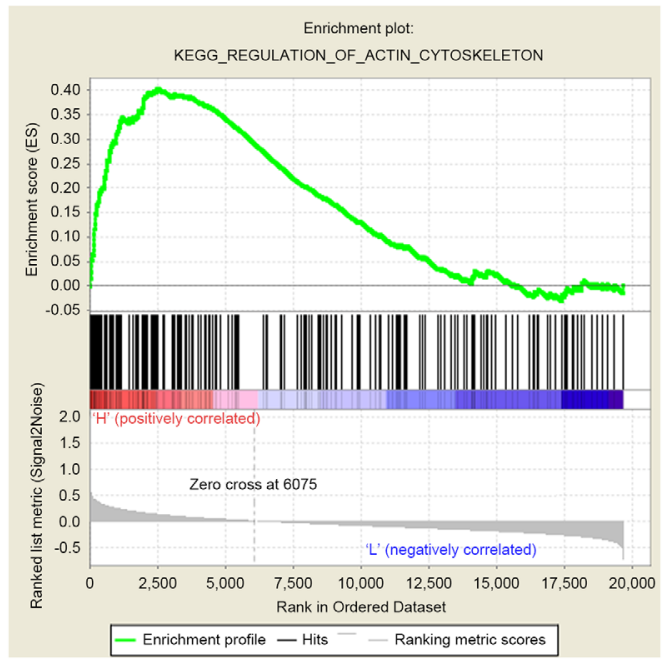

Figure 8. Human epididymis protein 4, ANXA2 and P-glycoprotein genes were commonly enriched in the signaling pathway involved in the regulation of the actin cytoskeleton. with exogenous active HE4 protein. There was no significant difference in hsa-miR-129-5p between the untreated group and treated group by IgG in CAOV3 cells (P>0.05; Fig. 7B). Data from these tests further verified that the expression change in hsa-miR-129-5p was associated with $\mathrm{HE} 4$, which may require the involvement of ANXA2.

GSEA of HE4, ANXA2 and P-gp. In addition, since HE4 may participate in the development of multidrug resistance of OC at different levels, the GSEA network database was used to search for the common signaling pathways shared by HE4, ANXA2 and P-gp. GSEA results showed enrichment of both HE4 and ANXA2 genes in the signaling pathways regulating the actin cytoskeleton and focal adhesion, and ANXA2 and P-gp in the regulation of actin cytoskeleton, Toll-like receptor, chemokine and JAK-STAT signaling pathways. Notably, all three genes were commonly enriched in the signaling pathway involved in the regulation of actin cytoskeleton (Fig. 8). 


\section{Discussion}

Drug resistance of $\mathrm{OC}$ cells is a complex process involving multiple factors, levels and genes. Recent studies have indicated a close association of HE4 with drug resistance of OC cells $(8,9)$. Ribeiro et al (10) reported that increased HE4 expression in OC cells simultaneously induces resistance to both paclitaxel and carboplatin in vitro. Moreover, the MAPK signaling pathway and changes in the intracellular microtubule content and stability may be involved in this process (10). Another study suggests that HE4 affects the tumor microenvironment by interacting with epidermal growth factor receptor, insulin growth factor receptor and hypoxia-inducible factor-1 $\alpha$, thereby enhancing proliferative ability and inducing resistance to cisplatin in subcutaneous xenografts of nude mice (25). The collective results suggest that HE4 participates in the progress of multidrug resistance of $\mathrm{OC}$ at multiple levels.

It was shown that HE4 and ANXA2 were interacting proteins in OC cells. ANXA2 was required for HE4-mediated promotion of invasion and metastasis. The interactions between HE4 and ANXA2 facilitated the invasion and metastasis of OC cells, which was proposed to be attributed to ANXA2-assisted transfer of HE4 into the cell nucleus and consequent induction of invasion/metastasis-related genes (14). Several clinical and basic studies have confirmed that drug resistance and invasion/metastasis of malignant tumors are not two isolated processes but closely associated biological behaviors. In human drug-resistant human breast cancer cells, P-gp was proposed to promote migration and invasion through its associations with ANXA2 (15). Another study on gastric cancer cells reported that ANXA2 stimulates the expression of P-gp and the development of drug resistance by activating MAPK signaling pathway (19). These findings support the theory that HE4, ANXA2 and P-gp act in concert to play significant roles in the malignant biological behavior of cancer cells.

In the present study, both HE4 and ANXA2 were highly expressed in all three OC cell lines examined (CAOV3, OVCAR3 and SKOV3), while the expression of P-gp was slightly higher in CAOV3 compared with OVCAR3 and SKOV3 cells, which suggested HE4, ANXA2 and P-gp are widely expressed in OC cell lines. Co-immunoprecipitation experiments demonstrated co-expression between HE4 and ANXA2, as well as ANXA2 and P-gp, in CAOV3 cells. Colocalization of HE4/P-gp and ANXA2/P-gp was determined via immunofluorescent staining, indicating interactions among the three proteins. These results confirmed an association among HE4, ANXA2 and P-gp. In further experiments, it was found that drug resistance to adriamycin and the expression and activity of P-gp was significantly decreased after transfection in CAOV3 cells (CAOV3-HE4-L with decreased HE4 expression or CAOV3-A2-L with decreased ANXA2 expression). Experiments with paclitaxel were not performed in the present study, since other members of the team have used CAOV3 cells to perform experiments with paclitaxel (data unpublished). In addition, DC (liposomal adriamycin + carboplatin) has been recommended for the first-line chemotherapy regimen for ovarian cancer in 2019 NCCN guidelines (26). Treatment with exogenous active HE4 or ANXA2 protein induced a significant increase in P-gp in CAOV3 cells within
$24 \mathrm{~h}$, while treatment with HE4 or ANXA2 antibody significantly decreased the expression of P-gp. Co-treatment with ANXA2 antibody and active HE4 protein induced a decrease in $\mathrm{P}$-gp expression in CAOV3 cells. However, this expression pattern was not significantly reversed within $24 \mathrm{~h}$ after the treatment of CAOV3-A2-L cells with exogenous HE4 active protein. Therefore the present results have demonstrated that both HE4 and ANXA2 could regulate P-gp expression levels, thus resulting in P-gp-mediated drug resistance in OC cells. Furthermore, this effect may be associated with the interactions between HE4 and ANXA2, and so, it is speculated that $\mathrm{HE} 4$ promotes $\mathrm{P}$-gp-mediated drug resistance in OC cells through a mechanism requiring the participation of ANXA2.

Besides experiments in vitro, the relationship between HE4 and P-gp were further studied in human samples and confirmed that HE4 and P-gp are highly expressed and was positively associated in the tissues of drug-resistant patients with OC. Both HE4 and P-gp expression levels were associated with FIGO staging and chemoresistance. High expression of $\mathrm{HE} 4$ or P-gp was an independent risk factor for poor prognosis of $\mathrm{OC}$, highlighting the significance of histopathological examination of HE4 and P-gp expression in predicting drug resistance and prognosis for patients with OC.

To further elucidate the detailed mechanisms by which the interactions between $\mathrm{HE} 4$ and ANXA2 regulate $\mathrm{P}-\mathrm{gp}$ expression and lead to drug resistance in ovarian cancer cells, five miRNAs that potentially bind the $\mathrm{P}$-gp gene, ABCB1, were predicted using bioinformatics and their associations with HE4/ANXA2 were explored. miRNAs are single-stranded small RNA molecules $21-23$ bases in length. In plants and animals, miRNAs directly formed RNA-induced silencing complexes to degrade mRNA or repress translation through base-pairing with the 3'-UTR region of target mRNAs, thereby participating in post-transcriptional regulation (27). Among the five miRNAs, expression of hsa-miR-129-5p was particularly increased after transfection in CAOV3 cells, indicating that the expression of hsa-miR-129-5p is consistent with those of HE4, ANXA2 and P-gp. The addition of exogenous active HE4 or ANXA2 protein significantly suppressed the expression of hsa-miR-129-5p in CAOV3 cells within $24 \mathrm{~h}$ while treatment with HE4 antibody, ANXA2 antibody or ANXA2 antibody with HE4 active protein led to a remarkable increase in hsa-miR-129-5p expression. Treatment of CAOV3-A2-L cells with exogenous active HE4 protein did not lead to a significant reversal of the hsa-miR-129-5p expression pattern within $24 \mathrm{~h}$, indicating that the expression of hsa-miR-129-5p was associated with HE4, which may require the involvement of ANXA2. The increased expression of miR-129-5p in human drug-resistant gastric cancer cells was reported to decrease drug resistance, and data from the luciferase reporter system further demonstrated that three multidrug resistance genes, including $\mathrm{ABCB} 1$, are target genes of miR-129-5p (28). Consistently, it was proposed that HE4, through its interactions with ANXA2, regulates hsa-miR-129-5p, then regulates P-gp, thereby enhancing drug resistance of OC cells. In addition to the mechanism involving miRNA, utilization of the TCGA database for GSEA of HE4, ANXA2 and P-gp revealed that all three genes are involved in the regulation of the actin cytoskeleton signaling, which is closely associated with the development of drug resistance 
in tumor cells (29). Furthermore, knockout or knockdown or point mutation of $\mathrm{P}$-gp will be conducted in order to study the biological behaviors of CAOV3 in future studies.

In summary, HE4 and P-gp are associated with OC development, both displaying high expression in the tissues of drug-resistant patients with OC. The present study has shown for the first time that ANXA2 interacts and colocalizes with $\mathrm{P}-\mathrm{gp}$ in $\mathrm{OC}$ cells, suggesting that HE4 promotes $\mathrm{P}$-gp-mediated $\mathrm{OC}$ resistance through interactions with ANXA2, which led to poor prognosis. Furthermore, this mechanism may be associated with decreased expression of hsa-miR-129-5p and dysregulation of the actin cytoskeleton signaling pathway. The present study results highlight novel targets for the clinical treatment of drug-resistant $\mathrm{OC}$ and provide a theoretical basis for developing effective new chemotherapy regimens. However, the specific molecular pathway by which HE4 regulates the expression and activity of $\mathrm{P}$-gp requires further study.

\section{Acknowledgements}

Not applicable.

\section{Funding}

This work was supported by the National Natural Science Foundation of China (grant nos. 81672590, 81472437, 30872757 and 81602304) and the Outstanding Scientific Fund of Shengjing Hospital (grant no. 201303).

\section{Availability of data and materials}

The datasets used and/or analyzed during the current study are available from the corresponding author on reasonable request.

\section{Authors' contributions}

QL and BL confirm the authenticity of all the raw data. QL performed the experiments, acquired the data and drafted the manuscript. DWL, HMW and SJ collected human OC tissues, and performed the immunohistochemistry and western blotting experiments. MJZ analyzed and interpreted the GSEA data. JJL, YYH, LCZ and LD were involved in the in vitro cell experiments and drafting the manuscript. BL participated in the conception and experimental design of the project. All authors read and approved the final manuscript, and agreed to be accountable for all aspects of the research in ensuring that the accuracy or integrity of any part of the work are appropriately investigated and resolved.

\section{Ethics approval and consent to participate}

Samples were fully encoded to protect patient confidentially. The study and its protocols were approved by the Research Ethics committees of Shengjing Hospital Affiliated with China Medical University (IACUC permit no. 2020PS277K). Since all the samples used in the study were discarded, the informed consents were not needed, which was approved by the ethics committees.

\section{Patient consent for publication}

Not applicable.

\section{Competing interests}

The authors declare that they have no competing interests.

\section{References}

1. Kipps E, Tan DS and Kaye SB: Meeting the challenge of ascites in ovarian cancer: New avenues for therapy and research. Nat Rev Cancer 13: 273-282, 2013.

2. Baguley BC: Multiple drug resistance mechanisms in cancer. Mol Biotechnol 46: 308-316, 2010.

3. Baguley BC: Multidrug resistance in cancer. Methods Mol Biol 596: 1-14, 2010.

4. Mechetner EB and Roninson IB: Efficient inhibition of P-glycoprotein-mediated multidrug resistance with a monoclonal antibody. Proc Natl Acad Sci USA 89: 5824-5828, 1992.

5. Breier A, Gibalova L, Seres M, Barancik M and Sulova Z: New insight into p-glycoprotein as a drug target. Anticancer Agents Med Chem 13: 159-170, 2013.

6. Gibalová L, Sereš M, Rusnák A, Ditte P, Labudová M, Uhrík B, Pastorek J, Sedlák J, Breier A and Sulová Z: P-glycoprotein depresses cisplatin sensitivity in L1210 cells by inhibiting cisplatin-induced caspase-3 activation. Toxicol In Vitro 26: 435-444, 2012.

7. Hellström I, Raycraft J, Hayden-Ledbetter M, Ledbetter JA, Schummer M, McIntosh M, Drescher C, Urban N and Hellström KE: The HE4 (WFDC2) protein is a biomarker for ovarian carcinoma. Cancer Res 63: 3695-3700, 2003.

8. Aarenstrup Karlsen M, Høgdall C, Nedergaard L, Philipsen Prahm K, Schou Karlsen NM, Weng Ekmann-Gade A, Henrichsen Schnack T, Svenstrup Poulsen T, Jarle Christensen I and Høgdall E: HE4 as a predictor of adjuvant chemotherapy resistance and survival in patients with epithelial ovarian cancer. APMIS 124: 1038-1045, 2016.

9. Nassir M, Guan J, Luketina H, Siepmann T, Rohr I, Richter R, Castillo-Tong DC, Zeillinger R, Vergote I, Van Nieuwenhuysen E, et al: The role of HE4 for prediction of recurrence in epithelial ovarian cancer patients-results from the OVCAD study. Tumour Biol 37: 3009-3016, 2016.

10. Ribeiro JR, Schorl C, Yano N, Romano N, Kim KK, Singh RK and Moore RG: HE4 promotes collateral resistance to cisplatin and paclitaxel in ovarian cancer cells. J Ovarian Res 9: 28, 2016.

11. Tanaka T, Akatsuka S, Ozeki M, Shirase T, Hiai H and Toyokuni S: Redox regulation of Annexin II and its implications for oxidative stress-induced renal carcinogenesis and metastasis. Oncogene 23: 3980-3989, 2004.

12. Bjørnland K, Winberg JO, Odegaard OT, Hovig E, Loennechen T, Aasen AO, Fodstad O and Maelandsmo GM: S100A4 involvement in metastasis: Deregulation of matrix metalloproteinases and tissue inhibitors of matrix metalloproteinases in osteosarcoma cells transfected with an anti-S100A4 ribozyme. Cancer Res 59: 4702-4708, 1999.

13. Mathisen B, Lindstad RI, Hansen J, El-Gewely SA, Maelandsmo GM, Hovig E, Fodstad O, Loennechen T and Winberg JO: S100A4 regulates membrane induced activation of matrix metalloproteinase-2 in osteosarcoma cells. Clin Exp Metastasis 20: 701-711, 2003.

14. Zhuang H, Tan M, Liu J, Hu Z, Liu D, Gao J, Zhu L and Lin B: Human epididymis protein 4 in association with Annexin II promotes invasion and metastasis of ovarian cancer cells. Mol Cancer 13: 243, 2014.

15. Zhang F, Zhang H, Wang Z, Yu M, Tian R, Ji W, Yang Y and Niu R: P-glycoprotein associates with Anxa2 and promotes invasion in multidrug resistant breast cancer cells. Biochem Pharmacol 87: 292-302, 2014.

16. Zhang ZD, Li Y, Fan Q, Zhao B, Tan B and Zhao XF: Annexin II is implicated in multi-drug-resistance in gastric cancer through p38MAPK and AKT pathway. Neoplasma 61: 627-637, 2014.

17. Li N, Yang L, Wang H, Yi T, Jia X, Chen C and Xu P: MiR-130a and MiR-374a function as novel regulators of cisplatin resistance in human ovarian cancer A2780 Cells. PLoS One 10: e128886, 2015. 
18. Jung H, Kim JS, Kim WK, Oh KJ, Kim JM, Lee HJ, Han BS Kim DS, Seo YS, Lee SC, et al: Intracellular Annexin II regulates $\mathrm{NF}-\kappa \mathrm{B}$ signaling by binding to the p50 subunit: Implications for gemcitabine resistance in pancreatic cancer. Cell Death Dis 6: e1606, 2015.

19. Zhang R, Lu M, Zhang Z, Tian X, Wang S and Lv D: Resveratrol reverses P-glycoprotein-mediated multidrug resistance of U2OS/ADR cells by suppressing the activation of the NF- $\kappa \mathrm{B}$ and p38 MAPK signaling pathways. Oncol Lett 12: 4147-4154, 2016.

20. FIGO Committee on Gynecologic Oncology: Current FIGO staging for cancer of the vagina, fallopian tube, ovary, and gestational trophoblastic neoplasia. Int J Gynaecol Obstet 105: 3-4, 2009.

21. Morgan RJ Jr, Copeland L, Gershenson D, Locker G, McIntosh D, Ozols R and Teng N; The National Comprehensive Cancer Network: NCCN ovarian cancer practice guidelines. Oncology (Williston Park) 10 (Suppl 11): 293-310, 1996.

22. Zhuang H, Gao J, Hu Z, Liu J, Liu D and Lin B: Co-expression of Lewis y antigen with human epididymis protein 4 in ovarian epithelial carcinoma. PLoS One 8: e68994, 2013.

23. Livak KJ and Schmittgen TD: Analysis of relative gene expression data using real-time quantitative PCR and the 2(-Delta Delta C(T)) Method. Methods 25: 402-408, 2001.

24. Wang H, Tan M, Zhang S, Li X, Gao J, Zhang D, Hao Y, Gao S, Liu J and Lin B: Expression and significance of CD44, CD47 and c-met in ovarian clear cell carcinoma. Int J Mol Sci 16: 3391-3404, 2015.
25. Moore RG, Hill EK, Horan T, Yano N, Kim K, MacLaughlan S, Lambert-Messerlian G, Tseng YD, Padbury JF, Miller MC, et al: HE4 (WFDC2) gene overexpression promotes ovarian tumor growth. Sci Rep 4: 3574, 2014.

26. Armstrong DK, Alvarez RD, Bakkum-Gamez JN, Barroilhet L, Behbakht K, Berchuck A, Berek JS, Chen LM, Cristea M, DeRosa M, et al: NCCN guidelines insights: Ovarian cancer, Version 1. J Natl Compr Canc Netw 17: 896-909, 2019.

27. Kim VN and Nam JW: Genomics of microRNA. Trends Genet 22: 165-173, 2006.

28. Wu Q, Yang Z, Xia L, Nie Y, Wu K, Shi Y and Fan D: Methylation of miR-129-5p CpG island modulates multi-drug resistance in gastric cancer by targeting $\mathrm{ABC}$ transporters. Oncotarget 5: 11552-11563, 2014.

29. Islam SU, Shehzad A, Sonn JK and Lee YS: PRPF overexpression induces drug resistance through actin cytoskeleton rearrangement and epithelial-mesenchymal transition. Oncotarget 8: 56659-56671, 2017.

(i) (3) This work is licensed under a Creative Commons Attribution-NonCommercial-NoDerivatives 4.0 International (CC BY-NC-ND 4.0) License. 